\title{
Optimization of nutritional constituents for carbonic anhydrase production by Bacillus mucilaginosus K02
}

\author{
Zhicai Zhang ${ }^{1,2}$, Bin Lian" ${ }^{1 *}$ Weiguo $\mathrm{Hou}^{1}$, Mingxia $\mathrm{Chen}^{2}, \mathrm{Xin}_{\mathrm{Li}^{2}}$, Wangli Shen ${ }^{2}$ and $\mathrm{Yan}_{\mathrm{Li}}^{3}$ \\ ${ }^{1}$ State Key Laboratory of Environmental Geochemistry, Institute of Geochemistry, Chinese Academy of Sciences, \\ Guiyang, Guizhou 550002, P. R. China. \\ ${ }^{2}$ School of Food and Biological Engineering, Jiangsu University, Zhenjiang 212013, P. R. China. \\ ${ }^{3}$ School of Foreign Language, Jiangsu University, Zhenjiang 212013, P. R. China.
}

Accepted 27 May, 2011

\begin{abstract}
The objective of this study was to optimize the submerged cultured conditions of carbonic anhydrase (CA) production from the strain of Bacillus mucilaginosus $\mathrm{K02}$ by mono-factor tests with blank control and orthogonal design methodology. When the bacteria was cultured under the condition of monofactor tests with blank control and orthogonal designs, and conventional mono-factor test and orthogonal designs, respectively, the CA productions increased from $5.32 \mu \mathrm{U} / \mathrm{L}$ under the basic medium to 34.53 and $26.12 \mu \mathrm{U} / \mathrm{L}$. The kinetic analysis of $5 \mathrm{~L}$-fermentor showed that the specific production rate of $C A$ in the optimized medium was almost equaled to the one obtained in the basic and optimized medium with conventional methods. The result demonstrated that CA synthesis was positively correlated with cell growth, and the mono-factor tests with blank control applied in the optimizing composition of the media could achieve better results in contrast to the conventional method.
\end{abstract}

Key words: Bacillus mucilaginosus, carbonic anhydrase, specific production rate, kinetic analysis, orthogonal design.

\section{INTRODUCTION}

Carbonic anhydrase (CA), which catalyzes the hydration of carbon dioxide and dehydration of dicarbonate, exists in most living organism (Smith and Ferry, 2000; llies and Banciu, 2004). Some studies showed that the amount of soluble calcium increased with increasing CA activities and indicated that CA increased solubility of calcium and magnesium ions from carbonate rock ( $\mathrm{Li}$ et al., 2005; Nathalie et al., 2009; Li et al., 2007). Therefore, CA may be applied in recovery and utilization of atmospheric $\mathrm{CO}_{2}$, weathering and formation of carbonate rock.

Bacillus mucilaginosus $\mathrm{K} 02$ has been reported to possess strong ability to release mineral elements from various rocks and has widely been used in bacterial biofertilizer and biological leaching (Lian et al., 2001; Sheng and He, 2006; Sugumaran and Janarthanam, 2007). Since CA activity (especially exo-cellular CA activity) can increase the concentrations of mineral ions in soil, to

*Corresponding author. E-mail: bin2368@vip.163.com. Tel: +86851-5895148. Fax: +86-851-5895148. optimize the condition and analyze kinetics for CA production from bacterium $\mathrm{K} 02$ is necessary in order to enhance the efficiency of K02 strain as biofertilizer.

The optimal design of the culture medium is one of the most important steps in the food microbiology and fermentation (Kim et al., 2005). The conventional methods for the optimization of the culture media are to select the optimum factors by mono-factor experiment firstly and then to optimize the content of each factor by orthogonal test and response surface methodology (Zheng et al., 2008; Mu et al., 2009). All these methods are based on the mono-factor design. The shortcoming of the methods is that they neglect the fact that a special metabolite may be synthesized through multi-steps reaction and these reactions usually are catalyzed by many different enzymes, which normally require different co-factors or prosthetic groups. For example, iron and magnesium play the roles of electron carrier and prosthetic group in some kinases, respectively. To know if one factor facilitates metabolic synthesis, the results must be compared with in the present factor in the absence of the factor (the blank control) instead of among a type of different factors (in 
conventional methods). Therefore, the optimization efficiency fails to reach the best results by conventional methods although orthogonal test and response surface methodology are applied.

In a previous work, we have proven that $B$. mucilaginosus $\mathrm{K} 02$ can fix atmospheric $\mathrm{CO}_{2}$ by capturing $\mathrm{CO}_{2}$ with carbonic anhydrase (Zhang et al., 2011). In this study, the fermentation conditions for $B$. mucilaginosus K02 to synthesize CA was optimized by mono-factor designs with blank control and orthogonal designs and the kinetics of CA synthesis were compared in three media, including the optimum medium. The technologic condition from the study provides a presupposition for further investigation of the structure and function of $\mathrm{CA}$ synthesized by $B$. mucilaginosus $\mathrm{K} 02$ and increasing mineral ions' solubility in soil and micro-elements content induced by $B$. mucilaginosus $\mathrm{K} 02$ and $\mathrm{CA}$.

\section{MATERIALS AND METHODS}

\section{Microbial strain}

The bacterial strain, Bacillus mucilaginosus K02 (GenBank database accession number: HM579819, stored at Environmental Biological Science and Technology Research Center, Institute of Geochemistry, Chinese Academy of Sciences), used in this study was isolated from soil samples collected from the maize-farming fields in the nearby suburbs of Guiyang City, Guizhou Province, China and maintained in the State Key Laboratory of Environmental Geochemistry, Institute of Geochemistry, Chinese Academy of Sciences (Lian et al., 2008).

\section{Reagents}

The following reagents: 4-Nitrophenyl acetate (pNPA), $p$-nitrophenol and Diethymalonic acid were purchased from Sigma-Aldrich (USA), while sucrose assay kits were purchased from Jiancheng Biological Insititute, Nanjing, Jiangsu. All other reagents were local products of analytical grade.

\section{Fermentation medium and culture conditions}

The basic culture media contained (g/L): sucrose 5.0, $\mathrm{Na}_{2} \mathrm{HPO}_{4}$ 2.0, $\mathrm{MgSO}_{4} \cdot 7 \mathrm{H}_{2} \mathrm{O} \quad 0.5, \mathrm{CaCO}_{3} \quad 0.1, \mathrm{FeCl}_{3} \cdot 6 \quad \mathrm{H}_{2} \mathrm{O} \quad 0.005$ and glass powder (10). Inoculum was obtained by inoculating the bacterium in a $250-\mathrm{mL}$ flask containing $100 \mathrm{~mL}$ of basal medium and incubated at $32^{\circ} \mathrm{C}$ in a rotary shaker at $150 \mathrm{rpm}$ for 4 days, after which $2 \%$ $(\mathrm{v} / \mathrm{v})$ inoculums were added aseptically to $250 \mathrm{~mL}$ flasks containing $100 \mathrm{~mL}$ of the afore-stated basic culture medium. The culture was incubated for 6 days at $32^{\circ} \mathrm{C}$.

\section{Fermentation in bioreactor}

The fermentation medium was inoculated with $2 \%(\mathrm{v} / \mathrm{v})$ seed culture and then cultivated at $32^{\circ} \mathrm{C}$ in a $5 \mathrm{~L} \mathrm{~B}$. Braun Biostat $\mathrm{Q}$ fermenter (B. Braun, Germany) was equipped with $\mathrm{pH}$ and dissolved oxygen electrodes. Unless otherwise specified, fermentations were operated under the following conditions: temperature $\left(32^{\circ} \mathrm{C}\right)$, initial $\mathrm{pH}(6.0)$, aeration rate (1 vvm), agitation speed $(120 \mathrm{rpm})$ and working volume $(4 \mathrm{~L})$. A comparative fermentation was also operated under the same conditions in B. Braun Biostat $Q$ fermenter.

\section{Analytical methods}

The samples collected at different intervals from the shake-flask or B. Braun Biostat $Q$ fermenter cultures were centrifuged at $6000 \mathrm{rpm}$ for $20 \mathrm{~min}$, and the supernatant was used as CA enzyme solution in enzymatic activity assay. The activity of CA was assayed with the colorimetric method according to Verpoorte et al. (1967) with certain modifications. The reactive mixture consisted of $1 \mathrm{~mL}$ enzyme solution and $1 \mathrm{~mL} \mathrm{pH} 6.4$, while $0.2 \mathrm{~mol} / \mathrm{L}$ phosphate buffer contained $1 \mathrm{mmol} / \mathrm{L} \mathrm{pNPA}$ and $0.01 \mathrm{mmol} / \mathrm{L}$ diethmalonic acid. The reaction was then carried out at $35^{\circ} \mathrm{C}$ for 30 min. The released $p$ nitrophenol was calculated by the increase in absorbance at 400 $\mathrm{nm}$ and the standard curve of $p$-nitrophenol, and $1 \mathrm{~mL}$ enzyme solution was replaced by $1 \mathrm{~mL}$ distilled water as control. The activity of CA was expressed by one unit of enzymatic activity, which represented the amount of enzyme required to produce $1 \mu \mathrm{mol} p$ nitrophenol per min under the assay conditions.

Residual glycerol in broth was assayed by refraction analysis with LR35B portable refractometer according to Robert and Ragno (2007). The residual sucrose of broth was determined by Sucrose assay kits (Jiancheng Biological Institute) according to the manufacturer's protocols, while the $\mathrm{pH}$ of broth was determined with a PHS $-3 \mathrm{C}+\mathrm{pH}$ meter. All analyses were performed with three replications. Cell growth was estimated by measuring the optical density at $660 \mathrm{~nm}$ (721 Visible Spectrometer).

\section{Estimation procedures in fermentation kinetics}

The bacterial specific growth rate was determined according to the following equation:

$\mu\left(\mathrm{h}^{-1}\right)=\frac{1}{X} \times \frac{d X}{d t}$

Where, $X$ is the bacterial concentration $(\mathrm{g} / \mathrm{L})$ and $t$ is the culture time (d).

The specific consumption rate of glycerol in broth was estimated according to the following equation:

$$
Q_{S / X}[\mathrm{~g} /(g \cdot \mathrm{h})]=\frac{1}{X} \times \frac{d S}{d t}
$$

Where, $S$ is the substrate concentration $(\mathrm{g} / \mathrm{L})$ and $t$ is the culture time (d).

The specific production rate of carbonic anhydrase was estimated according to the following equation:

$$
P_{P / X}[\mathrm{~g} /(g \cdot \mathrm{h})]=\frac{1}{X} \times \frac{d P}{d t}
$$

Where, $P$ is the CA concentration $(\mathrm{g} / \mathrm{L})$ and $t$ is the culture time $(\mathrm{h})$.

\section{RESULTS AND DISCUSSION}

\section{Effect of $\mathrm{pH}$ and temperature}

In order to find the optimal temperature for enzyme 


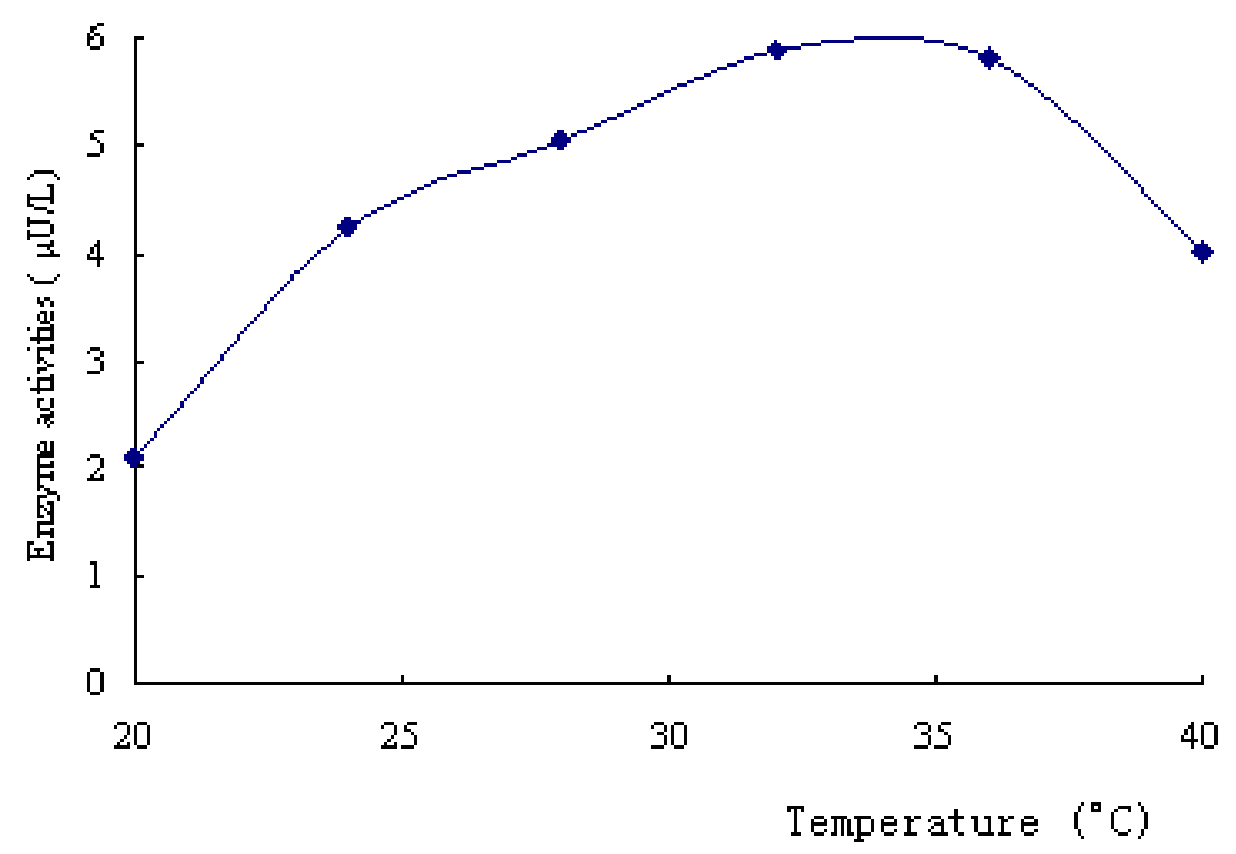

Figure 1. Effect of different temperature on product of carbonic anhydrase.

production, B. mucilaginosus $\mathrm{K} 02$ was cultivated at different temperatures, where the range of optimum temperature was 32 to $36^{\circ} \mathrm{C}$ (Figure 1). Taking into account that the enzyme is easy to inactivate under high temperature, $32^{\circ} \mathrm{C}$ is regarded as an optimal fermentation temperature of the bacterial. A similar result was obtained in the submerged culture of silicate bacterium LNNZY-2 for spore ( $\mathrm{Li}$ et al., 2009) and B. mucilaginosus for biomass (Liu et al., 2002). To investigate the effect of initial $\mathrm{pH}$ on enzyme activities, the organism was cultivated in the media with different initial $\mathrm{pH}$ (4.0 to 7.5) in shake flask cultures. The optimal $\mathrm{pH}$ range for enzyme production was 5.5 to 6.5 (Figure 2), which is different from the optimal $\mathrm{pH}$ of $B$. mucilaginosus for biomass production (Liu et al., 2002). The discrepancy was explained with the fact that the optimal conditions for biomass and CA production were different.

\section{Effect of carbon and nitrogen sources}

To find a suitable carbon source for enzyme production, the bacterium was cultured in basic media in which sucrose was replaced by different carbon sources at 20 $\mathrm{g} / \mathrm{L}$ for 6 days. As shown in Figure 3, glycerol, sucrose, maltose and xylose were used as carbon sources, but the highest enzyme activity was obtained when glycerol was used as a carbon source. In normal condition, the $\mathrm{CO}_{2}$ hydrate reaction naturally occurred in the absence of CA, but the speed was lower than in the presence of $C A$, in that CA could accelerate the speed rate of the reaction. When glucose and fructose were used as carbon sources, the production which could inhibit the $\mathrm{CO}_{2}$ hydrate reaction was synthesized, so the negative enzyme activities were assayed. Subsequently, it would be shown that glycerol was used as a carbon source in orthogonal designs.

Although, it had been reported that $B$. mucilaginosus could fix atmospheric nitrogen, it is not clear whether nitrogen, fixed by the bacterial itself, meets the requirement of bacterial CA synthesis or not. So it is necessary to investigate the effect of nitrogen sources on CA production. The bacterium was cultured in a basic medium where different nitrogen sources were added at a concentration of $0.5 \mathrm{~g} / \mathrm{L}$ for 6 days and no nitrogen source provided was used as a blank control. Yeast extract, ammonium sulfate and potassium nitrate could markedly elevate enzymatic activities in the broth. Beef extract and peptone also increased enzyme production compared with blank control, but the increasing amount of enzyme production was less in contrast to yeast extract, ammonium sulfate and potassium nitrate (Figure 4). However, urea was the only nitrogen source to decrease CA (Figure 4). Yeast extract, ammonium sulfate and potassium nitrate were used as multiple nitrogen sources in the following orthogonal designs.

\section{Effect of mineral element and growth factors}

The mineral elements were naturally occurring substances and their growth factors could not be synthesized, or the amount synthesized was too small to meet their growth requirement. The mineral elements and growth factors facilitated cellular growth, proliferation and cellular differentiation and played a critical role in 


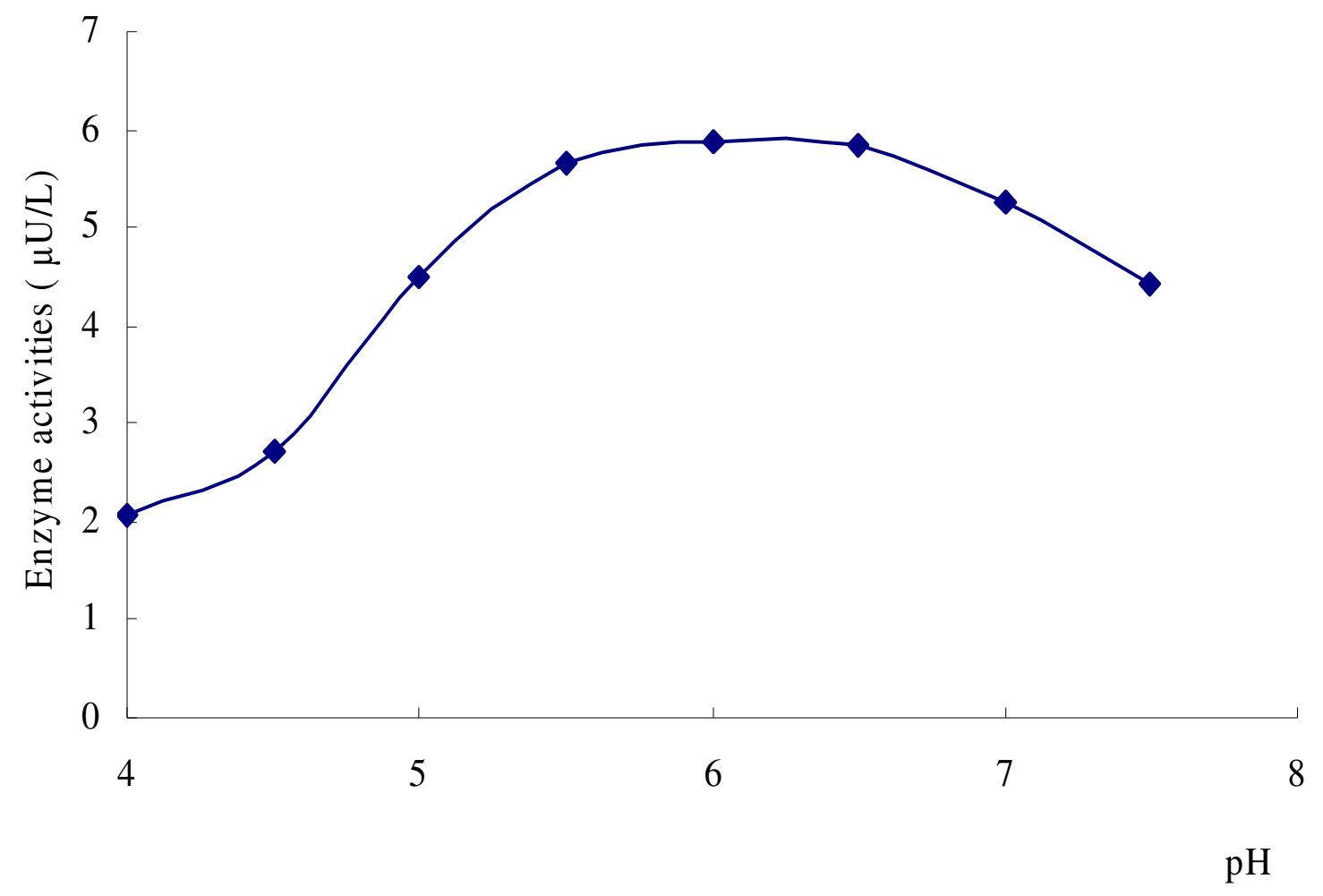

Figure 2. Effect of different $\mathrm{pH}$ on product of carbonic anhydrase.

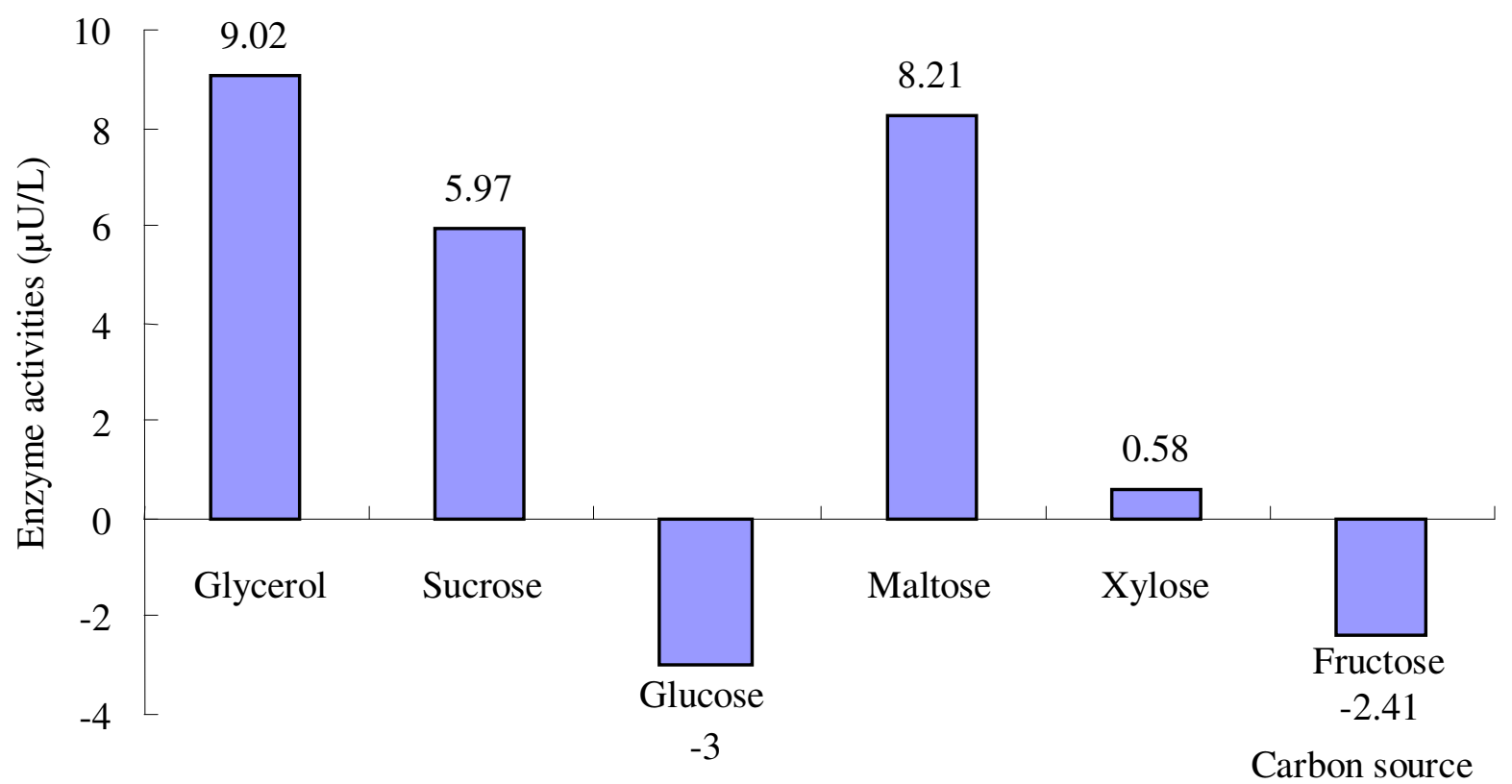

Figure 3. Effect of different carbon sources on product of carbonic anhydrase.

regulating the direction of metabolism flow. Therefore, the effect of mineral elements and growth factors on CA production was investigated. The bacterial was cultured in basic medium by adding different mineral salts at a concentration of $0.002 \mathrm{~g} / \mathrm{L}$ and growth factors at a concentration of $0.001 \mathrm{~g} / \mathrm{L}$ for 6 days, and neither the mineral salt nor growth factor provided was used as a blank control. Nonetheless, magnesium sulfate, sodium 


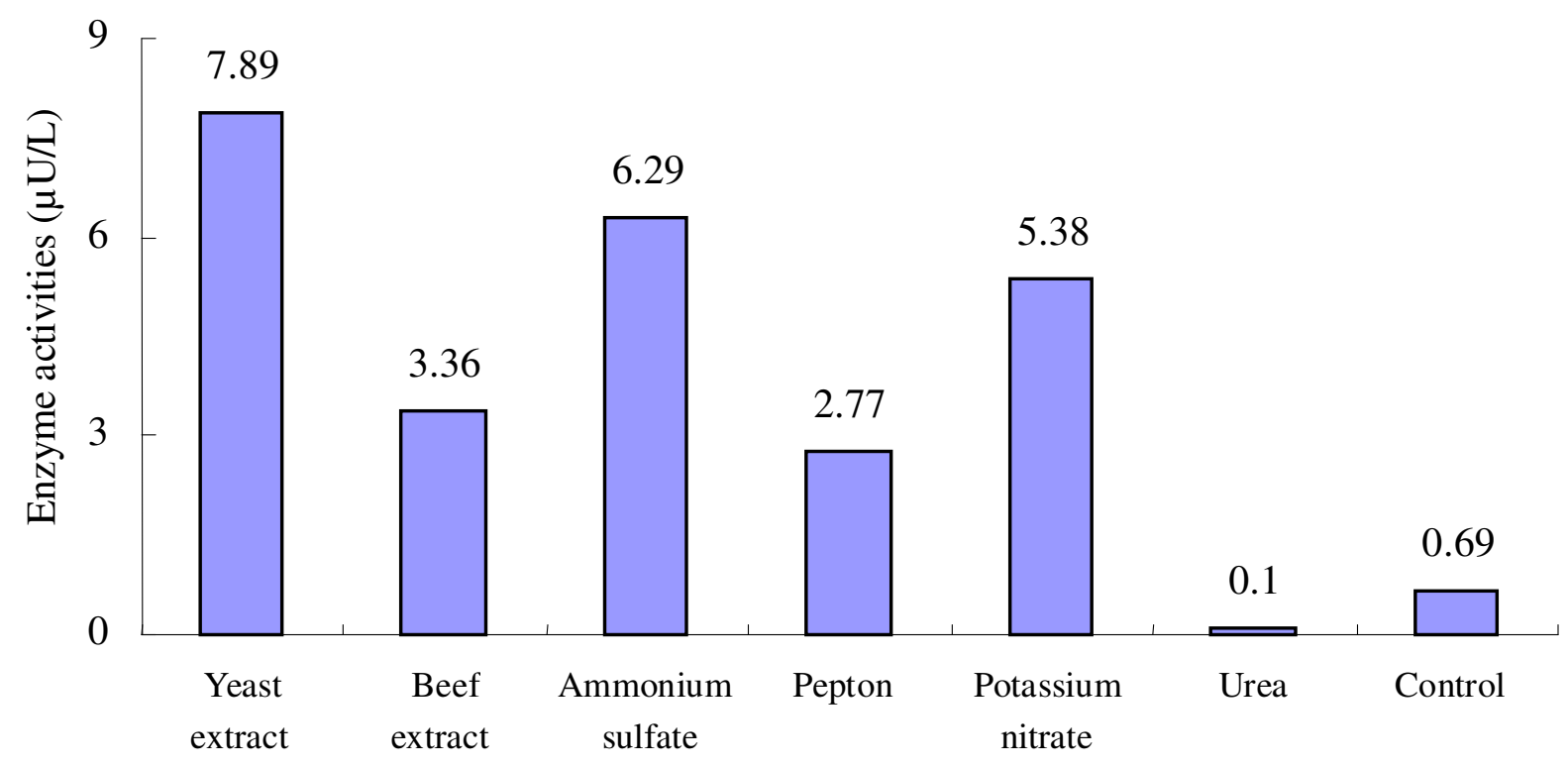

Nitrogen source

Figure 4. Effect of different nitrogen sources on product of carbonic anhydrase.

molybdate and borax (Figure 5) and 3, 5-dinitrosalylic acid (Figure 6) all increased enzyme production compared to the blank control.

\section{Running results of orthogonal matrix design}

The $X^{4}$ factorial design, a factorial arrangement with 4 factors at all $X$ levels, was employed. Four factors were set in from 2 to 5 columns, respectively. Each factor was set as an $X$ level and expressed as a natural number from 1 to $X$, respectively. In the table of each orthogonal design project, the value in parentheses behind the level of each factor represented the concentration in the level of the factor. The number in the last column of the orthogonal table was the experimental result of each project and the mean of the triplicate. During the optimized experiments, the fermentations were carried out in a rotary shaking incubator at $150 \mathrm{rpm}$ and $32^{\circ} \mathrm{C}$ for 7 days. The initial $\mathrm{pH}$ of the medium was adjusted to 6.0. The analysis of running results was indicated as $\mathrm{k}_{\mathrm{i}}$ (following orthogonal design project), which expressed the average value of all experiments at the same factor level. The last line in the orthogonal matrix method showed the range of the factor, which was equal to maximum (average of $\mathrm{k}_{\mathrm{i}}$ ) to minimum (average of $\mathrm{k}_{\mathrm{i}}$ ).

The $4^{4}$ factorial design which is the minimum orthogonal matrix method, was used in the four factors and four levels orthogonal matrix design of carbon and nitrogen source. The four factors are glycerol, yeast extract, potassium nitrate and ammonium sulfate, and detailed experimental conditions for each project are listed in Table 1. The results showed that enzyme products were significantly different in the tested concentration of four factors. According to the order of magnitude of $R$, the order of effect of each factor on enzyme productions was potassium nitrate $>$ yeast extract > ammonium sulfate > glycerol. This result showed that the effect of potassium nitrate as a nitrogen source was more important than that of other nutrients. It could be demonstrated that the optimum carbon source and nitrogen in the medium were $(\mathrm{g} / \mathrm{L})$ : glycerol 40 , yeast extract $0.7, \mathrm{KNO}_{3} 0.3$ and $\left(\mathrm{NH}_{4}\right)_{2} \mathrm{SO}_{4}$ 0.3.

The $3^{4}$ factorial design which is the minimum orthogonal matrix method, was used in the four factors and three levels orthogonal matrix design of mineral elements and growth factor. The four factors are manganese sulfate, sodium molybdate, Borax and 3, 5dinitro salicylic acid, and detailed experimental conditions for each project are listed in Table 2. According to the order of magnitude of $\mathrm{R}$, the order of effect of all factors on enzyme productions was sodium molybdate $>$ magnesium sulfate $>$ borax $>3$, 5 -dinitro salicylic acid. This result showed that the effect of sodium molybdate was more important than that of other nutrients. It could be demonstrated that the optimum mineral elements and growth factors in the medium were $(\mathrm{g} / \mathrm{L}): \mathrm{MgSO}_{4} 0.05$, $\mathrm{Na}_{2} \mathrm{MoO}_{4} \quad 0.05, \quad \mathrm{Na}_{2} \mathrm{~B}_{4} \mathrm{O}_{7} \cdot 10 \mathrm{H}_{2} \mathrm{O} \quad 0.1$ and 3.5-dinitrosalicylic acid 0.02 (Table 2).

From the foregoing, the optimal medium for $B$. mucilaginosus $\mathrm{K} 02$ to synthesize CA was $(\mathrm{g} / \mathrm{L})$ : glycerol 40, yeast extract $0.7, \mathrm{KNO}_{3} 0.3$ and $\left(\mathrm{NH}_{4}\right)_{2} \mathrm{SO}_{4} \quad 0.3$, $\mathrm{MgSO}_{4} \quad 0.05, \mathrm{Na}_{2} \mathrm{MoO}_{4} \quad 0.05, \mathrm{Na}_{2} \mathrm{~B}_{4} \mathrm{O}_{7} \cdot 10 \mathrm{H}_{2} \mathrm{O} \quad 0.1$ and 3.5-dinitrosalicylic acid 0.02 . 


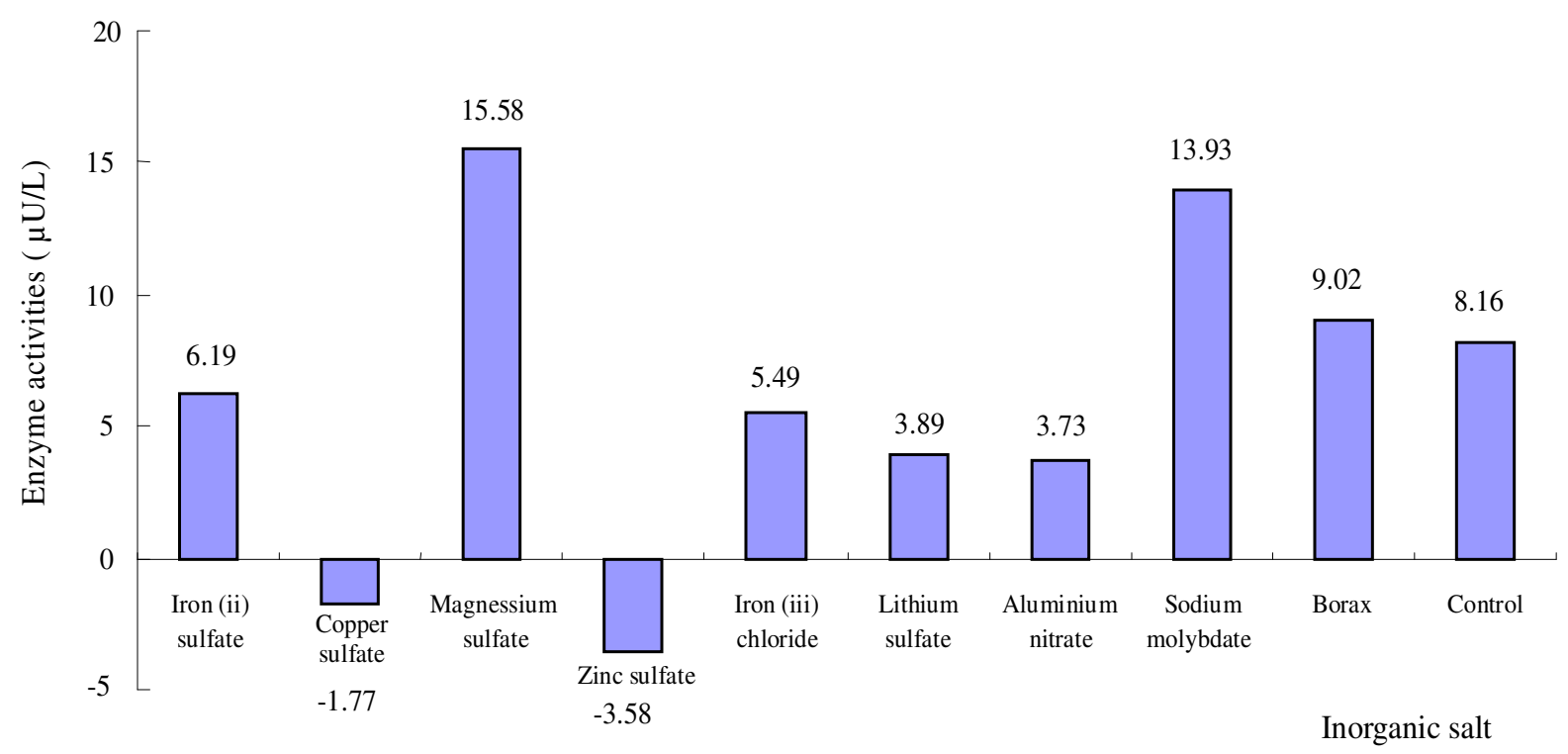

Figure 5. Effect of different inorganic salts on the product of carbonic anhydrase.

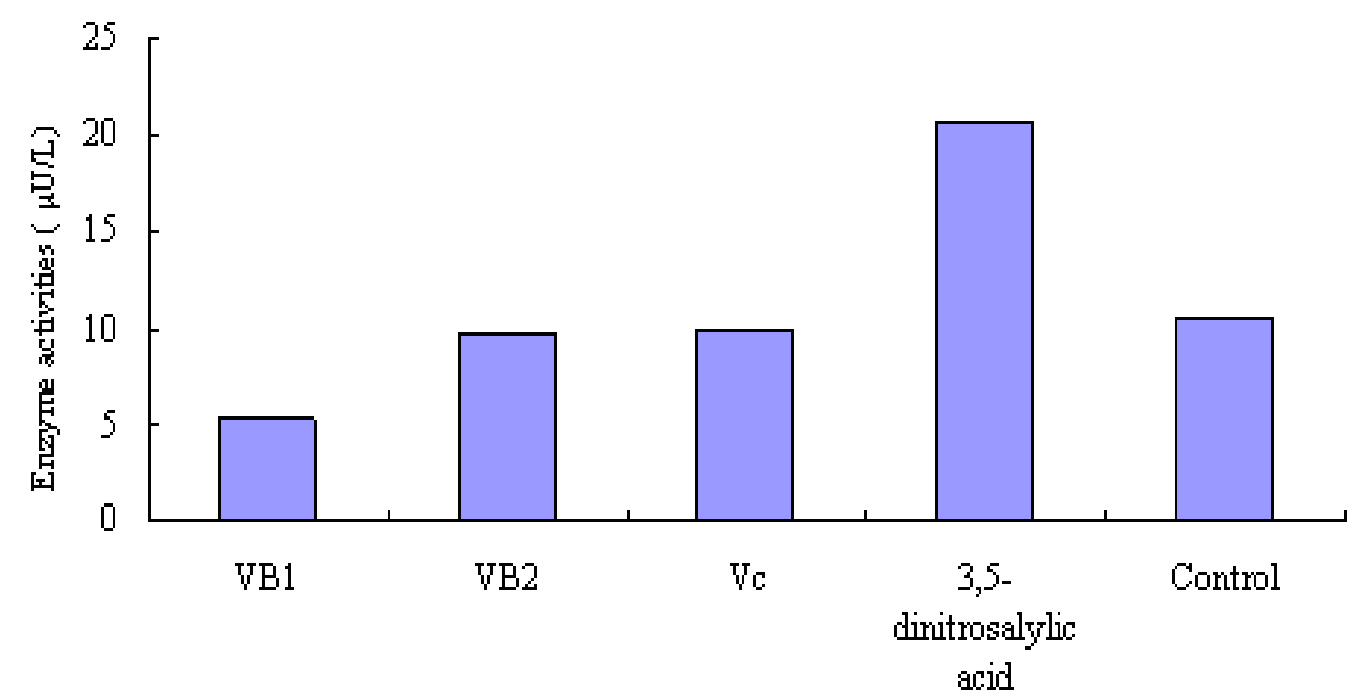

Growth factor

Figure 6. Effect of different growth factors on the product of carbonic anhydrase. VB1, VB2 and Vc are expressed as vitamin B1, B2 and $\mathrm{C}$, respectively.

Table 1. Application of $L_{16}\left(4^{5}\right)$ orthogonal projects in analyzing the effect of carbon and nitrogen source on activities of carbonic anhydrase.

\begin{tabular}{cccccc}
\hline $\begin{array}{c}\text { Test } \\
\text { number }\end{array}$ & $\begin{array}{c}\text { Glycerol } \\
(\%)\end{array}$ & $\begin{array}{c}\text { Yeast extract } \\
(\%)\end{array}$ & $\begin{array}{c}\text { Potassium } \\
\text { nitrate }(\%)\end{array}$ & $\begin{array}{c}\text { Ammonium } \\
\text { sulfate }(\%)\end{array}$ & $\begin{array}{c}\text { Enzymatic activity } \\
(\boldsymbol{\mu m o l} / \mathbf{m L})\end{array}$ \\
\hline 1 & $1(2)$ & $1(0.03)$ & $1(0.03)$ & $1(0.03)$ & 9.99 \\
2 & $1(2)$ & $2(0.07)$ & $2(0.07)$ & $2(0.07)$ & 6.72 \\
3 & $1(2)$ & $3(0.11)$ & $3(0.11)$ & $3(0.11)$ & 11.88 \\
4 & $1(2)$ & $4(0.15)$ & $4(0.15)$ & $4(0.15)$ & 11.21 \\
5 & $2(3)$ & $1(0.03)$ & $3(0.11)$ & $4(0.15)$ & 9.51 \\
\hline
\end{tabular}


Table 2. Application of $\mathrm{L}_{9}\left(3^{4}\right)$ orthogonal projects in analyzing the effect of micro-element and growth factor on activities of carbonic anhydrase.

\begin{tabular}{cccccc}
\hline $\begin{array}{c}\text { Test } \\
\text { number }\end{array}$ & $\begin{array}{c}\text { Manganese } \\
\text { sulfate (\%) }\end{array}$ & $\begin{array}{c}\text { Sodium } \\
\text { molybdate (\%) }\end{array}$ & Borax (\%) & $\begin{array}{c}\text { 3,5-dinitro } \\
\text { salicylic acid (\%) }\end{array}$ & $\begin{array}{c}\text { Enzymatic activity } \\
(\boldsymbol{\mu m o l} / \mathbf{m L})\end{array}$ \\
\hline 1 & $1(0.005)$ & $1(0.005)$ & $1(0.005)$ & $1(0.001)$ & 30.49 \\
2 & $1(0.005)$ & $2(0.010)$ & $2(0.010)$ & $2(0.0015)$ & 30.44 \\
3 & $1(0.005)$ & $3(0.015)$ & $3(0.015)$ & $3(0.002)$ & 28.41 \\
4 & $2(0.010)$ & $1(0.005)$ & $2(0.010)$ & $3(0.002)$ & 31.34 \\
5 & $2(0.010)$ & $2(0.010)$ & $3(0.015)$ & $1(0.001)$ & 27.18 \\
6 & $2(0.010)$ & $3(0.015)$ & $1(0.005)$ & $2(0.0015)$ & 26.06 \\
7 & $3(0.015)$ & $1(0.005)$ & $3(0.015)$ & $2(0.0015)$ & 30.81 \\
8 & $3(0.015)$ & $2(0.010)$ & $1(0.005)$ & $3(0.002)$ & 29.63 \\
9 & $3(0.015)$ & $3(0.015)$ & $2(0.010)$ & $1(0.001)$ & 28.67 \\
$\mathrm{k} 1^{\text {a }}$ & 29.78 & 30.88 & 28.73 & 28.78 & \\
$\mathrm{k} 2$ & 28.19 & 29.08 & 30.15 & 29.10 & \\
$\mathrm{k} 3$ & 29.70 & 27.71 & 28.80 & 29.79 & \\
$\mathrm{R}^{\mathrm{b}}$ & 1.59 & 3.17 & 1.42 & 1.01 & \\
\hline
\end{tabular}

${ }^{\mathrm{a}} \mathrm{ki}=\left(\sum \mathrm{kof}\right.$ all experiment at the same factor level $) / 3$. Values are mean of triple determinations. ${ }^{\mathrm{b}} \mathrm{R}=\max$ (average of $\mathrm{ki}$ ) - min (average of $\mathrm{k}$ i). Values are mean of triple determinations.

Table 2. continues

\begin{tabular}{cccccc}
\hline 6 & $2(3)$ & $2(0.07)$ & $1(0.03)$ & $3(0.11)$ & 19.22 \\
7 & $2(3)$ & $3(0.11)$ & $4(0.15)$ & $2(0.07)$ & 7.91 \\
8 & $2(3)$ & $4(0.15)$ & $2(0.07)$ & $1(0.03)$ & 8.20 \\
9 & $3(4)$ & $1(0.03)$ & $2(0.07)$ & $3(0.11)$ & 8.03 \\
10 & $3(4)$ & $2(0.07)$ & $4(0.15)$ & $1(0.03)$ & 15.59 \\
11 & $3(4)$ & $3(0.11)$ & $1(0.03)$ & $4(0.15)$ & 14.32 \\
12 & $3(4)$ & $4(0.15)$ & $3(0.11)$ & $2(0.07)$ & 8.65 \\
13 & $4(5)$ & $1(0.03)$ & $4(0.15)$ & $3(0.11)$ & 5.99 \\
14 & $4(5)$ & $2(0.07)$ & $2(0.07)$ & $4(0.15)$ & 10.25 \\
15 & $4(5)$ & $3(0.11)$ & $3(0.11)$ & $1(0.03)$ & 14.51 \\
16 & $4(5)$ & $4(0.15)$ & $1(0.03)$ & $2(0.07)$ & 12.10 \\
$\mathrm{k} 1^{\mathrm{a}}$ & 13.27 & 11.17 & 18.54 & 16.10 & \\
$\mathrm{k} 2$ & 14.95 & 17.26 & 11.06 & 11.79 & \\
$\mathrm{k} 3$ & 15.53 & 16.21 & 14.85 & 15.04 & \\
$\mathrm{k} 4$ & 14.28 & 13.39 & 13.57 & 15.10 & \\
$\mathrm{R}^{\mathrm{b}}$ & 2.26 & 6.09 & 7.48 & 4.31 & \\
\hline
\end{tabular}

${ }^{\mathrm{a}} \mathrm{ki}=\left(\sum \mathrm{kof}\right.$ all experiment at the same factor level $) / 3$. Values are mean of triple determinations; ${ }^{\mathrm{b}} \mathrm{R}=$ $\max ($ average of $\mathrm{k}$ ) - $\min$ (average of $\mathrm{k}$ ). Values are mean of triple determinations.

However, if blank control was not designed according to conventional methods, glycerol, yeast extract, magnesium sulfate and 3,5-dinitro salicylic acid were the optimum carbon source, nitrogen source, mineral salt and growth factor, respectively. The $3^{4}$ factorial designs were used in the four factors and three levels orthogonal matrix design, and the detailed experimental conditions for each project were listed in Table 3 . The analysis of running 
Table 3. Application of $L_{9}\left(3^{4}\right)$ orthogonal projects to optimize composition of medium with conventional method.

\begin{tabular}{cccccc}
\hline $\begin{array}{c}\text { Test } \\
\text { number }\end{array}$ & $\begin{array}{c}\text { Glycerol } \\
(\%)\end{array}$ & $\begin{array}{c}\text { Yeast extract } \\
(\%)\end{array}$ & $\begin{array}{c}\text { Magnesium } \\
\text { sulfate }\end{array}$ & $\begin{array}{c}\text { 3,5-dinitro } \\
\text { salicylic acid }\end{array}$ & $\begin{array}{c}\text { Enzymatic activity } \\
(\boldsymbol{\mu m o l} / \mathbf{m L})\end{array}$ \\
\hline 1 & $1(2)$ & $1(0.03)$ & $1(0.005)$ & $1(0.001)$ & 16.02 \\
2 & $1(2)$ & $2(0.07)$ & $2(0.010)$ & $2(0.0015)$ & 13.14 \\
3 & $1(2)$ & $3(0.11)$ & $3(0.015)$ & $3(0.002)$ & 15.65 \\
4 & $2(3)$ & $1(0.03)$ & $2(0.010)$ & $3(0.002)$ & 17.60 \\
5 & $2(3)$ & $2(0.07)$ & $3(0.015)$ & $1(0.001)$ & 20.79 \\
6 & $2(3)$ & $3(0.11)$ & $1(0.005)$ & $2(0.0015)$ & 18.98 \\
7 & $3(4)$ & $1(0.03)$ & $3(0.015)$ & $2(0.0015)$ & 19.44 \\
8 & $3(4)$ & $2(0.07)$ & $1(0.005)$ & $3(0.002)$ & 21.27 \\
9 & $3(4)$ & $3(0.11)$ & $2(0.010)$ & $1(0.001)$ & 22.91 \\
k1 & 14.94 & 17.69 & 18.76 & 19.91 & \\
k2 & 19.12 & 18.40 & 17.88 & 17.19 & \\
k3 & 21.21 & 19.18 & 18.63 & 18.17 & \\
R & 6.27 & 1.49 & 0.88 & \\
\hline a ki $=\left(\sum\right.$ kof all experiment at the same factor level $) / 3$. Values are mean of triple determinations. ${ }^{\mathrm{b}} \mathrm{R}=$ max \\
(average of ki) - min (average of $\mathrm{k}$ i). Values are mean of triple determinations.
\end{tabular}

results was shown from 11 to 14 lines and the range was shown in the last line. The optimum medium obtained from common methods was ( $\mathrm{g} / \mathrm{L})$ : glycerol 40 , yeast extract $0.11, \mathrm{MgSO}_{4} \mathrm{0.05}$, and 3.5-dinitrosalicylic acid 0.01 .

\section{The kinetic analysis of $B$. mucilaginosus $\mathrm{K} 02$ in $5 \mathrm{~L}$ fermenter}

The typical time courses of cell growth and CA production in $5 \mathrm{~L}$ fermentor under optimized medium, basic medium and medium obtained with conventional method are shown in Figures $7 \mathrm{a}, \mathrm{b}$ and $\mathrm{c}$. In the basic medium, the maximum bacterial biomass and CA activity were 0.89 and $5.32 \mu \mathrm{U} / \mathrm{L}$ at $132 \mathrm{~h}$, respectively. The bacterial growth rapidly increased from 24 to $120 \mathrm{~h}$ with a corresponding rapid increase of CA activity from 0.45 to $5.01 \mu \mathrm{U} / \mathrm{L}$, a decrease of sucrose concentration from 4.42 to $2.04 \mathrm{~g} / \mathrm{L}$, and an increase of $\mathrm{pH}$ from 6 to 6.9 (Figure 7a). In the optimized medium with the control, the maximum CA production was $33.42 \mu \mathrm{U} / \mathrm{L}$ at $120 \mathrm{~h}$, which was five times higher than that in the basic medium (Figure 7b) and significantly higher than that in the medium obtained with the conventional method $(26.16 \mu \mathrm{U} / \mathrm{L}$ at $132 \mathrm{~h}$ ) (Figure 7c). The kinetic parameters of bacterial growth with basic medium and optimized medium in a 5-L fermenter are comparatively illustrated in Figures $8 \mathrm{a}, \mathrm{b}$ and $\mathrm{c}$. The profile of specific growth rate and the specific production rate of CA during the fermentation process was almost similar among the three media, respectively, but the specific consumption rate of carbon source among the three media was significantly different. For the fact that specific production rate of CA is the ratio of velocity of CA synthesis and bacterial concentration, a certain correlation exists between the CA activity produced by bacterium and bacterial growth.

\section{Conclusion}

In conclusion, the optimum medium constituents for CA production of $B$. mucilaginosus $\mathrm{K} 02$ were successfully obtained in shake-flask cultures using the mono-factor tests with blank control and orthogonal design, which enabled the investigation of the influence of controlled factors in a multivariable system. Technological conditions for producing $\mathrm{CA}$ and the characteristic on $\mathrm{CA}$ synthesis obtained in the study will direct the study on structure and function of $\mathrm{CA}$, weathering mechanism of limestone and dissolution of mineral elements in the soil. The blank control in mono-factor test was applied to enhance the investigation of efficiency and achieve satisfied results in shorter time when compared to the conventional method.

\section{ACKNOWLEDGEMENTS}

This work was supported by a grant from the Ministry of Science and Technology of China (Grant No. 2006CB403200), National Natural Science Foundation of China (40773069), Chinese Postdoctoral Science Fund (Grant No. 20080440810) and Nantong social 


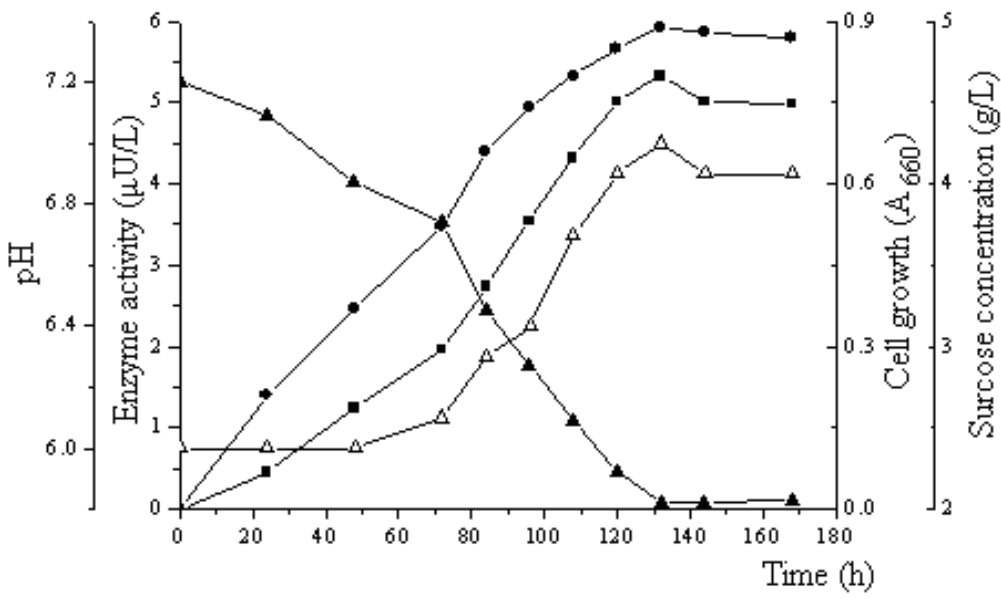

(a)

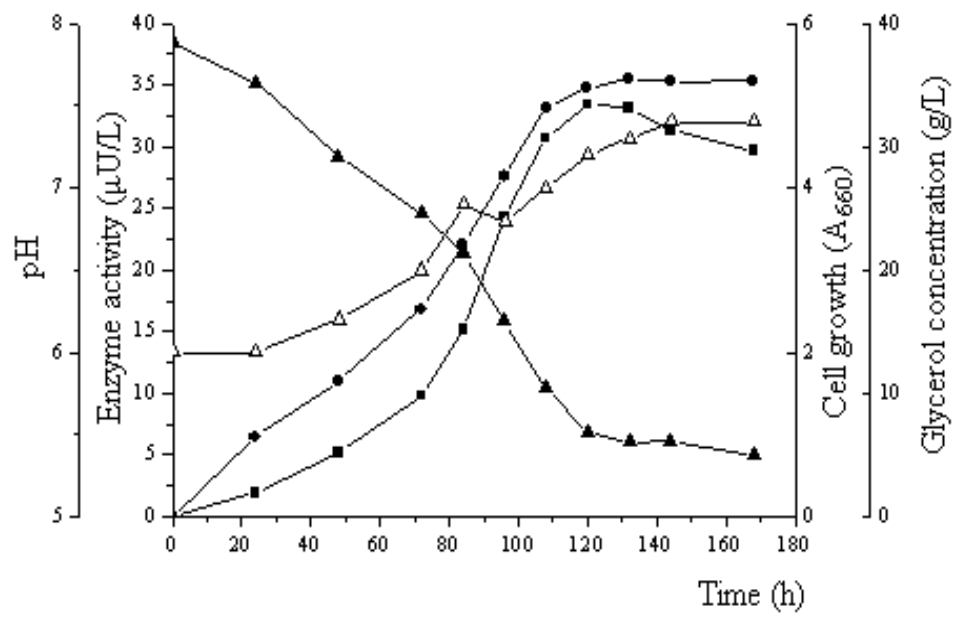

(b)

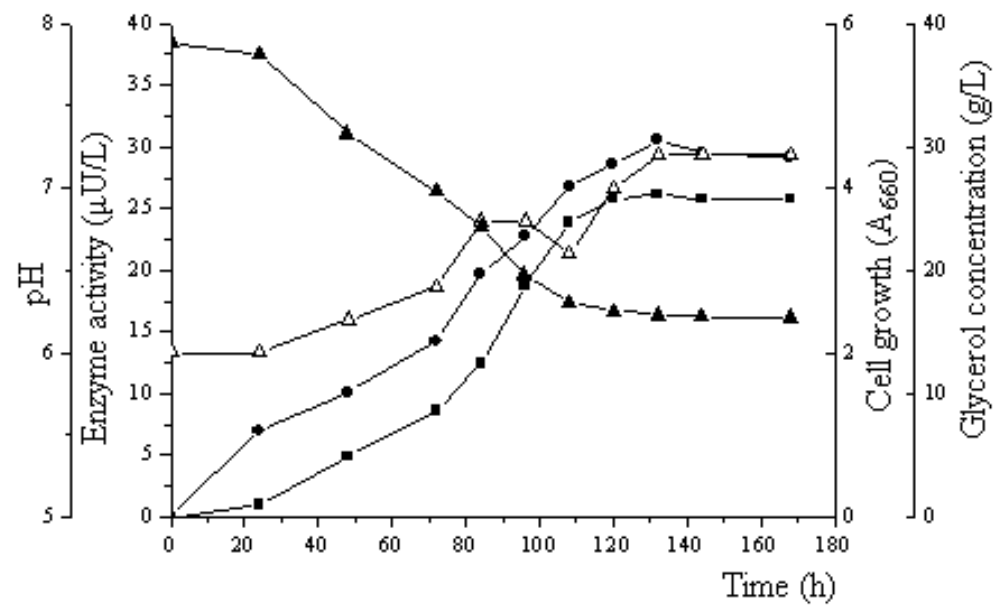

(c)

Figure 7. Typical time course of cell growth $(\bullet)$, CA production $(\boldsymbol{\bullet})$, carbon source consumption $(\boldsymbol{\Delta})$ and $\mathrm{pH}(\Delta)$ by Bacillus mucilaginosus $\mathrm{K} 02$ in a $5-\mathrm{L}$ B. Braun Biostat $Q$ fermenter (a) in basic medium, (b) in the optimized medium with blank control, and (c) in the medium obtained with the conventional method. 


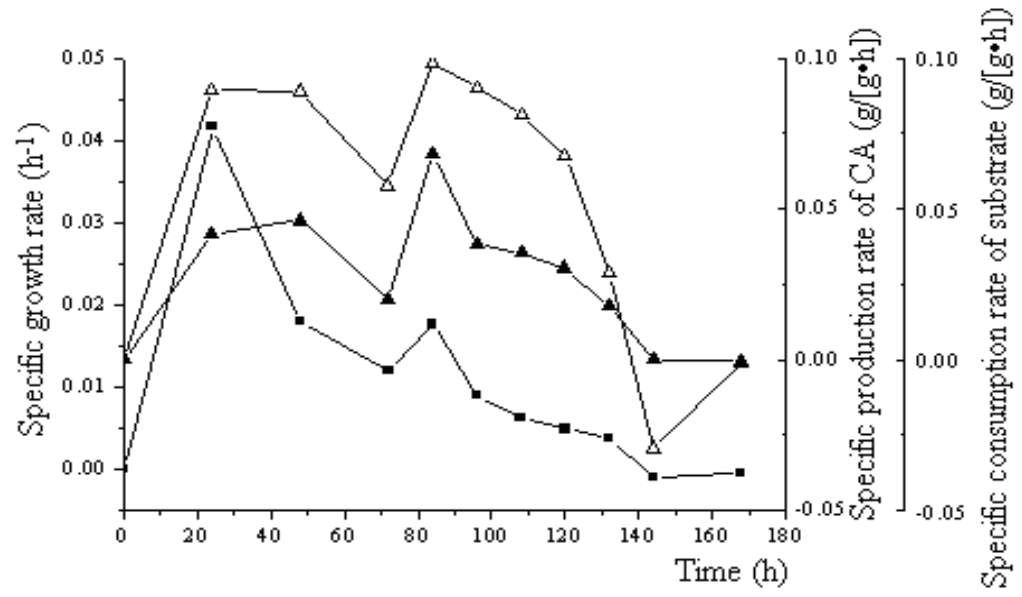

(a)

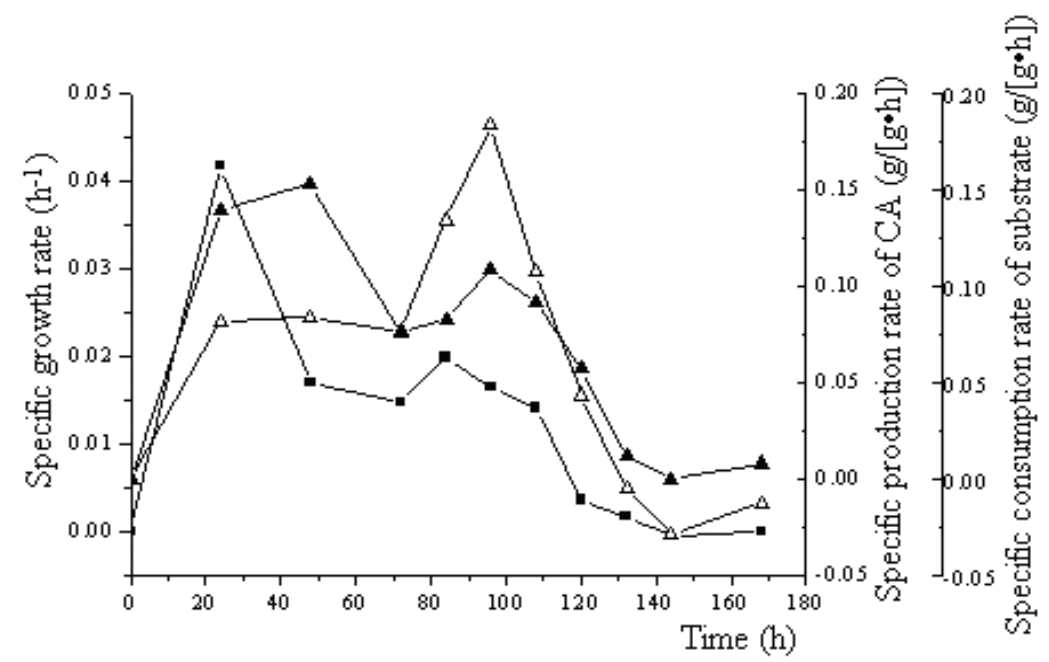

(b)

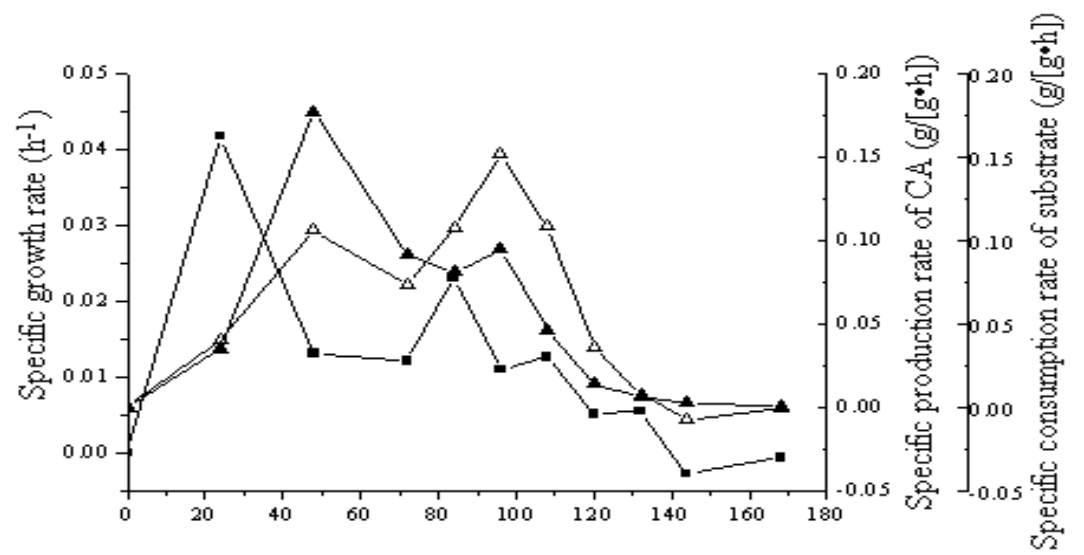

(c)

Figure 8. Kinetics analysis of specific growth rate (-), specific production rate of $\mathrm{CA}(\Delta)$ and specific consumption rate of substrate $(\boldsymbol{\Lambda})$ by Bacillus mucilaginosus K02 in a 5-L B. Braun Biostat Q fermenter (a) in basic medium, (b) in optimized medium with blank control, (c) in the medium obtained with the conventional method. 
development fund (S2008004). And a Project Funded by the Priority Academic Program Development of Jiangsu Higher Education Institutions.

\section{REFERENCES}

Ilies MA, Banciu MD (2004). Nonsulphonamide carbonic anhydrase inhibitors. In: Supuran CT, Andrea S, Janet C (eds) Carbonic anhydrase-its inhibitors and activators, CRC Press, USA.

Kim HO, Lim JM, Joo JH, Kim SW, Hwang HJ, Choi JW, Yun JW (2005). Optimization of submerged culture condition for the production of mycelial biomass and exopolysaccharides by Agrocybe cylindracea. Bioresour. Technol. 96: 1175-1182.

Lian B, ChenY, Zhao J, Teng HH, Zhu LJ, Yuan S (2008). Microbial flocculation by Bacillus mucilaginosus: Applications and mechanisms. Bioresour. Technol. 99: 4825-4831.

Lian B, Prithiviraj B, Souleimanov A, Smith DL (2001). Evidence for the production of chemical compounds analogous to nod factor by the silicate bacterium Bacillus circulans GY92. Microbiol. Res. 156: 289292.

Li W, Yu LJ, He QF, Wu Y, Yuan DX, Cao JH (2005). Effects of microbes and their carbonic anhydrase on $\mathrm{Ca}^{2+}$ and $\mathrm{Mg}^{2+}$ migration in columnbuilt leached soil-limestone karst systems. Appl. Soil Ecol. 29: 274281.

Li W, Yu LJ, Wu Y, Ji LP, Yuan DX (2007). Enhancement of $\mathrm{Ca}^{2+}$ release from limestone by microbial extracellular carbonic anhydrase. Bioresour. Technol. 98: 950-953.

Mu WM, Chen C, Li XF, Zhang T, Jiang B (2009). Optimization of culture medium for the production of phenyllactic acid by Lactobacillus $\mathrm{sp}$. SK007. Bioresour. Technol. 100: 1366-1370
Nathalie FM, Lorraine C, Alain CP (2009). Biocatalytic capture of $\mathrm{CO}_{2}$ with carbonic anhydrase and its transformation to solid carbonate. J. Mol. Catal B-Enzyme. 60: 163-170.

Robert Valeri C, Ragno G (2007). Use of supernatant osmolality and supernatant refraction to assess the glycerol concentration in glycerolized and deglycerolized previously frozen RBC. Transfus. Apher. Sci. 36: 133-137

Sheng XF, He LY (2006). Solubilization of potassium-bearing minerals by a wild-type strain of Bacillus edaphicus and its mutants and increased potassium uptake by Wheat. Can. J. Microbiol. 52: 66-72.

Smith KS, Ferry JG (2000). Prokaryotic carbonic anhydrases. FEMS Microbiol. Rev. 24: 335-366.

Sugumaran P, Janarthanam B (2007). Solubilization of potassium containing minerals by bacteria and their effect on plant growth. World J. Agric. Sci. 3: 350-355.

Verpoorte JA, Suchinta M, Edsall JT (1967). Esterase activities of human carbonic anhydrase B and C. J. Biol. Chem. 242: 4221-4229.

Zhang ZC, Lian B, Hou WG, Chen MX, Li X, Li Y (2011). Bacillus mucilaginosus can capture atmospheric $\mathrm{CO}_{2}$ by carbonic anhydrase. Afr. J. Microbiol. Res. 5(2): 106-112.

Zheng ZM, Hu QL, Hao J, Xu F, Guo NN, Sun Y, Liu DH (2008). Statistical optimization of culture conditions for 1,3-propanediol by Klebsiella pneumoniae AC 15 via central composite design. Bioresour. Technol. 99: 1052-1056. 